\title{
The Quran: Key Words in Context
}

The aim with the present series, The Quran: Key Words in Context, is to present the Quran as raw data with as little interpretation as possible.

The digital text used for this purpose is the Uthmani text of the Tanzil Quran Text (for attribution see the following page). This text is widely used, and we have conducted some comparison to pre-digital age printed editions of the Quran. All vocalized Arabic text is quoted unaltered in any shape or form from the Tanzil text. Unvocalized Arabic text and transcriptions are my own.

Each word in the Quran, in this volume adjectives, nouns, proper nouns and verbs which roots beginning with $\mathrm{Z} / \mathrm{j}$ through $1 / \varepsilon$, is presented in context, with five words to the right and left of it, where available or where the formating permits (keeping each quote on a single line).

In assigning each word a root and lemma, Classical dictionaries and Quran commentaries, as well as modern Quran dictionaries have been consulted. Deciding on these is not always obvious, since classical dictionaries and commentaries sometimes either disagree or present divergent variant readings or root and lemma attributions.

Words have been grouped by root > verbal form $>$ lemma. Verbs are quoted first (when attested), each followed by its associated nominal and/or adjectival derived forms. All are then sorted alphabetically according to Arabic and UNICODE order. In grouping the words, no attention has been given to the semantics of each word. Only on rare occasion have similar forms of words been separated in order to avoid morphological confusion. 